\title{
Psychological and Social Health Status of Patients with Lung Diseases in Jordan
}

\author{
Ayman M. Hamdan-Mansour1,2, Saleh N. Azzeghaiby3, Diana H. Arabiat'2, Talal H. Al Badawi ${ }^{3}$ \\ ${ }^{1}$ Department of Community Health Nursing, Al Farabi College, Riyadh, KSA \\ ${ }^{2}$ Faculty of Nursing, The University of Jordan, Amman, Jordan \\ ${ }^{3}$ Al-Farabi College, Riyadh, KSA \\ Email: a.mansour@ju.edu.jo, talal5656@yahoo.com, d.arabiat@ju.edu.jo
}

Received 22 March 2014; revised 27 April 2014; accepted 5 May 2014

Copyright (C) 2014 by authors and Scientific Research Publishing Inc.

This work is licensed under the Creative Commons Attribution International License (CC BY).

http://creativecommons.org/licenses/by/4.0/

c) (i) Open Access

\begin{abstract}
Objective: The study aim to investigate the psychosocial health status of patients with pulmonary diseases in Jordan. Methods: A cross-sectional survey using 230 patients diagnosed with lung diseases from six major hospitals in Jordan used to collect data in regards to depressive symptoms, psychological distress, coping, life satisfaction, and perceived social support. Data were collected from Jan 2013 to May 2013. Results: About 50\% of the patients reported moderate levels of ability to effectively cope with life situations, life satisfaction, psychological distress, and perceived social support from family, friends and others. About $29 \%$ of the patients reported that they had moderate to severe depressive symptoms. Depressive symptoms had significant and negative correlation with life satisfaction and perceived social support $(r=-0.21$ to $-0.39, p<0.001)$. Times of admissions $(\beta=2.72, p=0.007)$, marital status $(\beta=2.63, p=0.009)$, and life satisfaction $(\beta=-4.54$, $p \leq 0.001$ ) were the significant predictors of depressive symptoms. Conclusion: Health professionals need to screening for psychological disturbances for their patients. There should be integration between early detection of psychological disturbances and implementation of effective treatment plans.
\end{abstract}

\section{Keywords}

Depressive Symptoms, Psychological Distress, Coping, Life Satisfaction, Perceived Social Support, Lung Diseases

\section{Introduction}

The increasing comorbidity of chronic physical diseases and psychological health problems such as depression

How to cite this paper: Hamdan-Mansour, A.M., Azzeghaiby, S.N., Arabiat, D.H. and Al Badawi, T.H. (2014) Psychological and Social Health Status of Patients with Lung Diseases in Jordan. Health, 6, 1143-1151.

http://dx.doi.org/10.4236/health.2014.611141 
and stress raised the concern about this association on the overall individual health. According to Doumit and Nasser [1], patients with chronic illnesses are overwhelmed with psychological stressors due to requirement related to management of their illnesses. However, patients' psychosocial status may interfere with their ability to manage their needs independently that may exacerbate their health condition [2]. For example, patients with chronic illnesses may suffer unexplained symptoms, anxiety and depressive feelings that delay their recovery and healing process [3] [4]. Thus, patients with chronic illnesses are struggling to manage their physical illnesses independently and further overwhelmed with vulnerability to increased psychosocial co-morbidity [1].

The DSM-IV-TR states that approximately $20 \%$ to $25 \%$ of people with general medical conditions will become depressed during the course of their chronic condition [5]. International reports showed that patients diagnosed with chronic pulmonary conditions lead to impairments in activities of daily living, social functioning, psychological functioning, and recreational activities [6]. Reports also showed that chronic physical diseases have been associated with reduced health-related quality of life [7] [8]. In addition, depression among patients with pulmonary problems exacerbates the emotional and physical symptoms [9] [10]. The comorbidity between pulmonary diseases and psychological health problems appeared to have negative impact on severity of the disease, in particular and according to WHO, individuals with depression and co-morbid physical disorders had the worst overall health of all the disease states [11]. In an international study, role impairment was observed in about $50 \%$ in patients with chronic lung disease [12].

The impact of chronic illnesses on the bio-psycho-social aspects of individual's health and wellbeing cannot be interpreted solely in terms of disease process, but relates to difficulties of individuals' adjustment to their illnesses and the evolved changes of their lifestyle [13] [14]. Therefore, issues related to coping, social support, stress, optimism, and life satisfaction are significant in process of health-illness continuum. A recent study which investigated the level of psychological distress in a heterogeneous group of patients with pulmonary diseases reported significantly higher psychological distress among patients with pulmonary diseases than that among the general population [15] [16]. This emphasizes the importance of psychological support as a significant component of treatment modalities.

In Arabian region, and particularly in Jordan, management of chronic illnesses has showed growing interest for policy makers. However, the information related to psychological status of patients with chronic pulmonary diseases is limited. There is a need to explore the psychological and social wellbeing of those patients especially with the increased cost and demands for health care services globally. This study came to respond to these concerns and more to increase our knowledge in the field of mental and psychological wellbeing of patient with pulmonary diseases. The purpose of this study is to investigate the psychosocial health status of patients with pulmonary diseases in Jordan. The specific aims are:

- To determine the psychosocial health status of patients with pulmonary diseases in Jordan in regards to stress, depression, perceived social support, coping, optimism, and life satisfaction.

- To examine whether stress, social support, life satisfaction, and coping are significant predictors of depressive symptoms controlling for the demographic and personal characteristics of patients.

- To identify if the differences is the psychosocial health status of patients with pulmonary diseases in Jordan in relation to selected demographic and personal characteristics: age, gender, working status, and length of diagnosis.

\section{Methods}

Study design: A quantitative approach using cross-sectional, descriptive-correlational design was used to examine the psychosocial health status of patients with pulmonary diseases in Jordan. Data was from the three health care sectors in Jordan (governmental, educational and private). Information collected in regards to stress, depression, perceived social support, coping, optimism, and life satisfaction.

Sample and settings: Patients diagnosed with pulmonary diseases represented the population for this study. A convenience sampling of 230 patients completed and retuned the questionnaire. The study targeted patients attending primary, secondary and tertiary care units form six randomly major hospitals repressing the three health care sectors in Jordan. Data collected from Jan 2013 to may 2013. Inclusion criteria include: 1) patients diagnosed with pulmonary disease for longer than 6 months, 2) at age of 18 years or older, and 3) ability to read and write in Arabic. Exclusion criteria included: 1) no history of diagnosed mental or cognitive disorders.

Data collection procedure: Prior data collection, ethical approval obtained from the Faculty of Nursing at the 
University of Jordan, and the targeted institutions. Data collected using self report format. Patients who expressed interest to participation in the study were approached by the researcher who explained the study and provided them with all details and answered all their questions. Patients were asked to sign the consent letter that included information related to the title of the study, its purpose, its significance and a statement informing the participants that their privacy would be protected by assuring them that their responses will be treated confidentially, and information that reveal their identity will not be recorded. Also, they were assured that the information will be used for the purpose of the study, and that their participation is voluntary and they have the right to withdraw at any time during the study and that their decision will not influence the quality of care they receive. The whole package presented in Arabic language.

Instruments: The data collected using an Arabic version of self-reporting questionnaires. The English format of questionnaires consulted by a professional English language editor. To formulate the Arabic language format, a numbers of procedures used to determine the reliability and validity of the tool. The tool first translation into Arabic language by a professional English language editor and back translated into English language another independent professional English language editor as described by Brislin [17] and Chapman and Carter [18]. The two English forms (the original and the translated) compared in terms of conceptual and cultural appropriateness rather than literal meaning of the items by the primary and co-investigators who had the expertise in the field. The translator and the back translator meet to examine the difference in the two forms. Pilot testing conducted using patients $(n=25)$ requesting their appraisals for the appropriateness of the translation.

The instruments were:

1) Perceived social support was measured by Multidimensional Scale of Perceived Social Support [19]. This scale is 12-item self-reported scale to assess the perception of social support adequacy from the family, friends, and significant others such as health care team. Each item is measured using a 7-point Likert scale ranging from 1 (very strongly disagree) to 7 (very strongly agree). The scale has three sub scales, family (items $3,4,8, \& 11$ ), friends (items 7, 9, \& 12), and significant others (items 1, 2, 5, \& 10). The total score ranges from 7 to 84 . The higher the score is the higher the perceived social support. This scale had good internal consistency for the scale as whole which was 0.88. In this study, Cronbach's Alpha for the subscales were 0.85 (family), 0.79 (friends), and 0.75 (others).

2) The Beck Depression Inventory-II (BDI-II) [20] was used to assess patients' depressive symptoms, which contain items that measure cognitive-affective symptoms and attitudes, impaired performance, and somatic symptoms. This instrument contains 21 questions answered on a four-point Likert scale in which 0 represents the absence of symptoms and 3 represents an extreme problem. The total range of 0 to 63 and standard cutoff points as follow: 0 - 13 indicates no or minimal symptom, 14 - 19 indicates mild symptoms, 20 - 28 indicates moderate symptoms, and 29 - 63 indicates severe symptoms [20]. A score of 13 is the cut-off point indicating depression. The test-retest $\mathrm{r}$ was 0.88 , and Cronbach’s Alpha is 0.87 [20]. In this study, Cronbach's Alpha was 0.85 .

3) Stress was measured using the brief form of Psychological Stress Measure [21]. The original Psychological Stress Measure (PSM) was designed using 49 items drawn from descriptors generated by focus groups on stress. The scale is unifactorial in structure and maintains a test-retest stability of 0.68 to 0.80 under apparently constant conditions. Patients check the answer that best indicates the degree to which each statement has applied to him/her recently. The responses made on a Likert scale and ranged from range from 1 (null) to 4 (much). The higher the score in the scale reflect higher level of psychological stress. In this study, Cronbach's Alpha was 0.88 .

4) Coping skills were measured using the abbreviated version of the COPE Inventory [22]. Brief COPE is a 28 items scale measures the ways individuals use to cope with stress in their life. Brief COPE is formed of 14 domains (each consisted of 2 items) were responses ranged from 1 (I haven't been doing this at all) to 4 (I've been doing this a lot). The scale takes $>10$ minutes to be completed. The scale has good internal inconsistency with Cronbach's alpha of 0.83 [22]. In this study, Cronbach's alpha was 0.73 .

5) Life satisfaction was measured using the Satisfaction with Life Scale [23]. This is a general measure of life satisfaction, which consisted of five statements. Participants were asked to rate each statement according to the following seven-point scale: 1) strongly disagree, 2) disagree, 3) slightly disagree, 4) neither agree nor disagree, 5) slightly agree, 6) agree, and 7) strongly agree. The scores of the total scale ranges from 5 to 35 and interpreted as follow: from 31 - 35 (eextremely satisfied), from 26 - 30 (satisfied), from 21 - 25 (slightly satisfied), 20 (neutral), from 15 - 19 (slightly dissatisfied), from 10 - 14 (dissatisfied), and 5 - 9 (extremely dissatisfied). 
The test-retest reliability was estimated to be 0.87 [23]. In this study, Cronbach’s alpha was 0.78 .

Potential covariates: Gender, age, marital status, duration of disease, smoking status, income, education level and work status. The demographic information obtained from an investigator-developed subject profile.

\section{Results}

\subsection{Descriptive Characteristics}

A total number of 230 patients completed the questionnaire (see Table 1). Patients' age ranged from 19 to 90 years, with mean of $51.8(\mathrm{SD}=16.4)$. About $50.4 \%(\mathrm{n}=116)$ of the patients there were male patients, while 49.6\% ( $n=114)$ were females. In regard to marital status, the majority of them $70.9 \%(n=163)$ were married, while $2.2 \%(n=2)$ were divorced, and $12.2 \%(n=28)$ were single, and $12.6 \%(n=29)$ were widow. The analysis also showed that most of patients $(56.1 \%, n=129)$ were not working, and $22.2 \%(n=51)$ of them had a full time work, also $13.5 \%(n=31)$ had retired, where the least percent $8.3 \%(n=19)$ of patients had a part time work. The analysis also showed that the majority $(70.0 \%, \mathrm{n}=161)$ of patients were not smoking, while $30.0 \%(\mathrm{n}$ =69) were active smokers.

\subsection{Psychosocial Health Factors}

\subsubsection{Coping Skills}

Regarding patients' coping skills using brief COPE scale (see Table 1), the analysis showed that patients had a mean score of $70.3(\mathrm{SD}=10.3$ ) with scores ranging from 29 to 97 . Considering that the possible range of score is $28-112$, and that the analysis showed that $50 \%(n=115)$ of the patients had a score of 71.6 or above and $50 \%$ of them had a score between 65 and 67 , the results indicate that patients, in general, had moderate ability to effectively cope with their life situations.

\subsubsection{Psychological Distress}

Regarding patients' psychological distress level (see Table 1), the analysis showed that patients had a mean score of 42.6 ( $\mathrm{SD}=11.0$ ) with scores ranging from 15 to 68 . Considering that the possible range of score is 9 72 , and that the analysis showed that that $50 \mathrm{i} \%(\mathrm{n}=115)$ of the patients had a score of 42.6 or above and $50 \%$ of them had a score between 35 and 52, the results indicate that patients, in general, had moderate level of stress.

\subsubsection{Perceived Social Support}

Regarding patients' perception of perceived social support (see Table 2), the analysis showed that patients' highest perception of perceived social support was from others and family with mean scores of 21.2 (SD = 5.3) and $21.5(\mathrm{SD}=5.3)$ respectively. However, patients had lower perception of social support from friends with score of 17.8 (SD = 6.3). In general, perception of social support from family, friends and other were at the moderate level give the possible range of score for each subscale to be 4 - 28 and the median scores for all subscales were almost equal and at the moderate to high level (20 - 23). The analysis is showing the lowest level of perception was support from friends although the scores of seem to be at the moderate level.

\subsubsection{Life Satisfaction}

Regarding patients' satisfaction about their life (see Table 1), the analysis showed that patients had a mean score of 23.0 ( $S D=6.3$ ) with scores ranging from 5 to 35 . Considering that the possible range of score is 5 - 35, and that the analysis showed that $50 \%(n=115)$ of the patients had a score of 24 or above and $50 \%$ of them had a score between 19 and 27, the results indicate that patients, in general, had high level of satisfaction about their life.

\subsubsection{Depression}

Regarding depressive symptoms, the analysis (see Table 1) showed that the patients had a mean score of 16.9 ( $\mathrm{SD}=9.8$ ) with scores ranging from 0 to 54 . About $50 \%$ of the patients had a score of 16.0 or above and that $50 \%(n=115)$ had a score between 11 and 21. In regards to level of depression, the analysis showed that 34.3\% $(\mathrm{n}=79)$ of the patients found to have no or minimal depressive symptoms, while $36.5 \%(\mathrm{n}=84)$ had mild depressive symptoms, $17.0 \%(\mathrm{n}=39)$ had moderate depressive symptoms, and $12.2 \%(\mathrm{n}=28)$ had severe depres- 
Table 1. Psychosocial health status of patients diagnosed with lung disease in Jordan $(\mathrm{N}=230)$.

\begin{tabular}{cccccccc}
\hline Variable & $\mathbf{M}$ & SD & Min & Max & $\mathbf{P}_{\mathbf{2 5}}$ & $\mathbf{P}_{\mathbf{5 0}}$ & $\mathbf{P}_{\mathbf{7 5}}$ \\
\hline Life satisfaction & 23.0 & 6.3 & 5.0 & 35.0 & 19.0 & 24.0 & 27.0 \\
Social support-other & 22.1 & 5.3 & 4.0 & 28.0 & 20.0 & 23.5 & 26.0 \\
Social support-family & 22.5 & 5.2 & 4.0 & 28.0 & 19.0 & 22.2 & 25.0 \\
Social support-friends & 17.8 & 6.3 & 4.0 & 28.0 & 14.0 & 20.0 & 23.0 \\
Coping skills & 70.4 & 10.3 & 29 & 97.0 & 65.0 & 71.6 & 76.0 \\
Stress & 42.6 & 11.0 & 15 & 68.0 & 35.0 & 43.0 & 52.0 \\
Depression & 17.0 & 9.8 & 0.0 & 54.0 & 11.0 & 16.0 & 21.0 \\
\hline
\end{tabular}

Table 2. Correlation among psychosocial factors of patients diagnosed with lung disease in Jordan $(\mathrm{N}=230)$.

\begin{tabular}{|c|c|c|c|c|c|c|c|}
\hline & Depression & PSS-Other & PSS-Fa & PSS-Fr & Life Sat & Cope & Stress \\
\hline Depression & - & & & & & & \\
\hline PSS-other & $-0.21^{* *}$ & - & & & & & \\
\hline PSS-Fa & $-0.24^{* *}$ & $0.63^{* *}$ & - & & & & \\
\hline PSS-Fr & $-0.27^{* *}$ & $0.38^{* *}$ & $0.40^{* *}$ & - & & & \\
\hline Life Sat & $-0.39^{* *}$ & $0.41^{* *}$ & $0.33^{* *}$ & $0.22^{* * *}$ & - & & \\
\hline Cope & -0.10 & $0.30^{* *}$ & $0.17^{*}$ & $0.23^{* *}$ & $0.24^{* *}$ & - & \\
\hline Stress & 0.13 & 0.02 & 0.01 & -0.04 & 0.06 & $0.21^{* *}$ & - \\
\hline
\end{tabular}

${ }^{* *}$ Correlation is significant at the 0.01 level (2-tailed). ${ }^{*}$ Correlation is significant at the 0.05 level (2-tailed). PSS-Fr: Perceived social support from friends. PSS-Fa: Perceived social support from family. PSS-others: Perceived social support from others. Life Sat: Life satisfaction.

sive symptoms. The analysis indicates that about $65.7 \%$ of the patients are suffering from depressive symptoms, and $29 \%(n=67)$ had moderate to severe level of depression.

\subsection{Bivariate Analysis}

Using Pearson correlation coefficient (r), the analysis (see Table 2) showed that depressive symptoms had significant and negative correlation with life satisfaction, perceived social support from friends, family, and others, depressive symptoms ( $\mathrm{r}=-0.21$ to -0.39 , $\mathrm{p}<0.001$ ), while no significant correlation found between depressive symptoms and psychological distress and coping. In addition, life satisfaction has alcohol correlated positively and significantly with perceived social support from friends, family, and others, and coping ( $\mathrm{r}=0.22$ to 0.41 , $\mathrm{p}<$ 0.05). On the other hand, psychological distress had no significant correlation with any of the psychological or social health factors $(\mathrm{p}>0.05)$. The results indicate that those who have lower level of depression, higher level of social support (all forms) and positive coping skills are more likely to report higher level of life satisfaction.

To examine whether stress, social support, life satisfaction, and coping are significant predictors of depressive symptoms controlling for the demographic and personal characteristics (age, gender, working status, and medical diagnose), two-steps multiple hierarchical regression analysis was performed. The results (see Table 3) showed that model 1 that contained demographics and personal characteristics explained $17 \%\left(R^{2}=0.17\right)$ of the variance in depressive symptoms (see Table 3$)$. The model was also significant $\left(F_{9,203}=4.13, p<0.001\right)$. In this model, level of education $(\beta=-2.16,0.032)$, and times of admissions $(\beta=3.65, \mathrm{p}<0.001)$ and marital status $(\beta$ $=3.11,0.002)$ were the significant predictors of depression. After entry of stress, social support, life satisfaction, and coping at step 2, the total variance explained by the model as a whole was $33 \%\left(\mathrm{R}^{2}=0.33\right)$ and was significant $\left(\mathrm{F}_{15,230}=6.4, \mathrm{p}<0.001\right)$. The variables in step 2 explained an additional $16 \%$ of variance in depressive symptoms. In Model 2, times of admissions $(\beta=2.72$, $\mathrm{p}=0.007)$ and marital status $(\beta=2.63$, $\mathrm{p}=0.009)$ remained significant predictors; in addition; life satisfaction $(\beta=-4.54$, $\mathrm{p} \leq 0.001)$ was the only psychosocial predictor of depressive symptoms among all other factors.

\subsection{Differences in Psychosocial Health Status Related to Demographic Characteristics}

Regarding the relationship between demographic and personal characteristic and psychosocial factors, the analy- 
Table 3. Two steps Multiple Hierarchal Regressing depressive symptoms on stress, social support, life satisfaction, and coping controlling for demographic and personal characteristics among patients with lung diseases in Jordan $(\mathrm{N}=230)$.

\begin{tabular}{|c|c|c|c|c|}
\hline \multirow{2}{*}{ Variables } & \multicolumn{2}{|c|}{ Model 1} & \multicolumn{2}{|c|}{ Model 2} \\
\hline & $\beta$ & $\mathrm{p}$-value & $\beta$ & p-value \\
\hline Age & -0.64 & 0.536 & 0.45 & 0.652 \\
\hline Gender & -0.24 & 0.811 & -0.46 & 0.648 \\
\hline Marital status & 3.11 & 0.002 & 2.63 & 0.009 \\
\hline Working status & -1.44 & 0.151 & -1.22 & 0.226 \\
\hline Level of education & -2.16 & 0.032 & -1.97 & 0.050 \\
\hline Duration of medical diagnosis & 0.34 & 0.734 & 0.18 & 0.856 \\
\hline Times of admission & 3.65 & $<0.001$ & 2.72 & 0.007 \\
\hline Period of last admission & -1.36 & 0.175 & -0.14 & 0.888 \\
\hline Smoking status & -0.36 & 0.716 & 0.29 & 0.769 \\
\hline PSS-others & & & 0.35 & 0.724 \\
\hline PSS-Fa & & & -1.81 & 0.071 \\
\hline PSS-Fr & & & -1.90 & 0.059 \\
\hline Life Sat & & & -4.54 & $<0.001$ \\
\hline Cope & & & 0.36 & 0.723 \\
\hline Stress & & & 1.93 & 0.056 \\
\hline & & $\mathrm{p}$ & & $\mathrm{p}$ \\
\hline $\mathrm{R}^{2}$ & 0.17 & $<0.001$ & 0.33 & $<0.001$ \\
\hline Adjusted $\mathrm{R}^{2}$ & 0.13 & & 0.28 & \\
\hline $\mathrm{R}^{2}$ change & - & & 0.16 & \\
\hline
\end{tabular}

PSS-Fr: Perceived social support from friends. PSS-Fa: Perceived social support from family. PSS-others: Perceived social support from others. Life Sat: Life satisfaction.

sis showed that there was a positive correlation between patients' age and only perceived social support from family $(r=0.17, p<0.001)$ that indicts that older person had higher perception of social support from family. On the other hand, duration of medical diagnosis had negative and significant correlation with only perceived social support from others $(r=-0.15, \mathrm{p}<0.001)$ which indicates that those with longer period of diagnosis have higher perception of social support from others. All other psychosocial factors had no significant correlation with age or period of diagnosis.

Regarding gender, and using t-test for two independent sample, the analysis (see Table 4), showed that males and females patients were only different in their perception of social support from others $(t=-2.66, p<0.008)$, while all other psychosocial factors showed no significant differences. The analysis showed that female patients had higher perception compared to male ones. Regarding smoking status, the analysis (see Table 2), showed that there were significant differences in depressive symptoms and perceived social support from others between smoker and non-smokers ( $\mathrm{p}$ <.05). Smoker patients had higher depressive symptoms and lower perception of social support from others than nonsmokers. On the other hand, and using ANOVA test (see Table 4), and regarding working status, there was a significant difference between patients in regards to their working status related to depressive symptoms and perceived social support from friends $(\mathrm{p}<0.05)$. Using post hoc comparison (Scheffe test), the analysis showed that there was a significant difference in depressive symptoms between those who have full time job and those who are not working, while retired and those with part-time job were no difference in their depressive symptom than those working or not working.

\section{Discussion}

Psychosocial concerns are nearly universal among patients with chronic illnesses. Previous studies showed that psychological problems may exacerbate physical condition of individuals diagnosed with chronic illnesses [1]. 
Table 4. Differences in psychosocial factors related to demographic characteristics among patients diagnosed with lung disease $(\mathrm{N}=230)$.

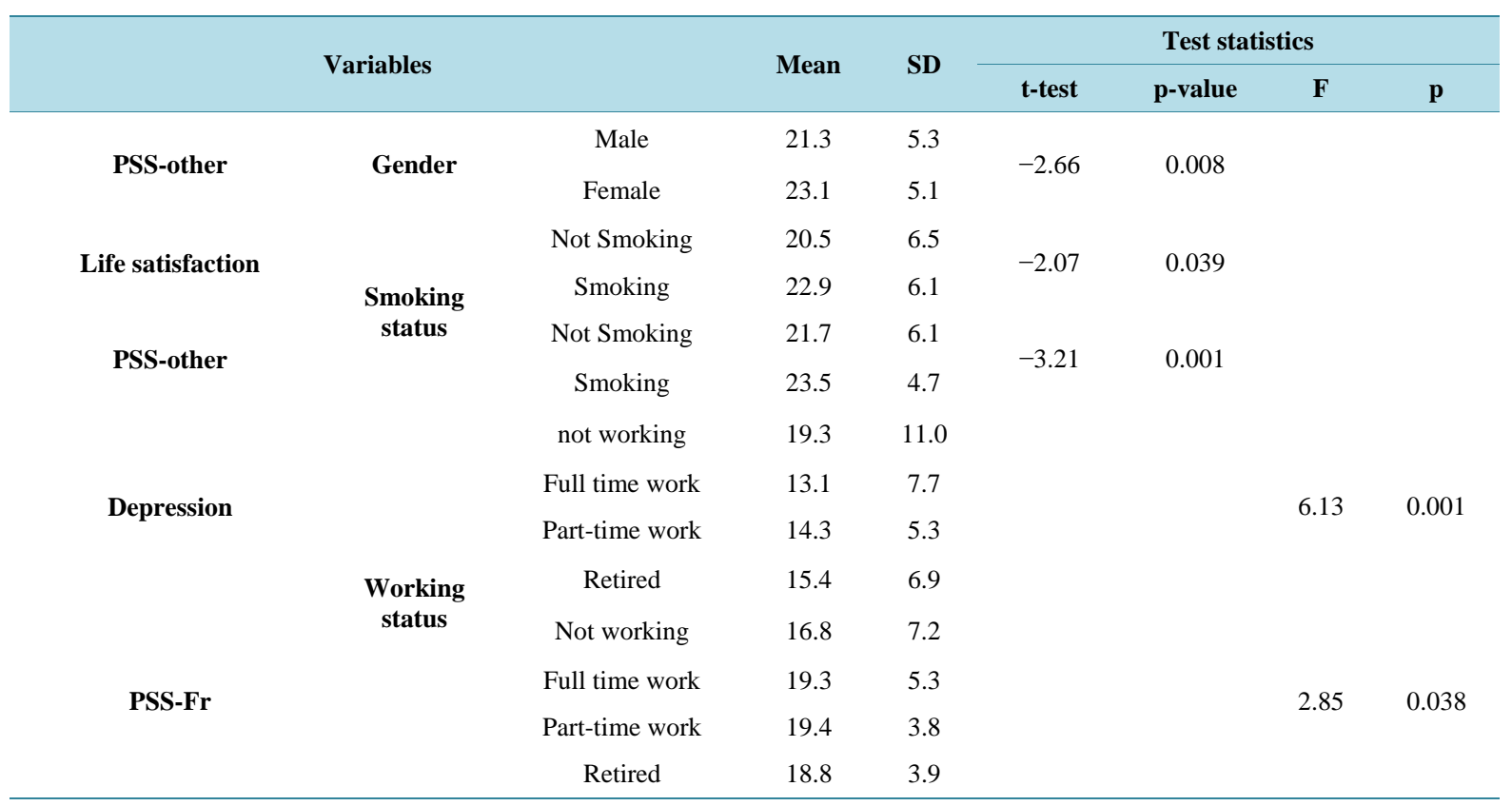

PSS-Fr: Perceived social support from friends. PSS-others: Perceived social support from others.

Therefore; screening for psychological factors among patients diagnosed with chronic illnesses became a primary concerns and requirement for health professional caring for this group of patients [24]. This study aimed at examining the psychological and social health factors among patients diagnosed lung diseases. The study found, in general, that patients diagnosed with lung diseases suffer psychological and social disturbances. Patients had moderate level of psychological and social wellbeing with significant number of them suffering moderate to severe depressive symptoms. Previous international studies found that chronic illnesses increased the vulnerability to psychological stressors and psychosocial co-morbidity [1] [24]. However, the results in this study do not completely support international reports as this study found moderate level of psychological distress and depressive symptoms. One possible explanation is that patients had also reported moderate level of satisfaction and social support, and had moderate ability to effectively manage their life situations. This may served as moderator to unpleasant experiences and distressing situation that are related to their illnesses and that may resulted in lowering levels of stress and depression. According to Cohen, Gottlieb and Underwood [25], social support influences health through stress-buffering model. The main premises of the stress-buffering model is that others will provide necessary resources that may redefine the potential for harm posed by a situation and cushions one's perceived ability to cope with imposed demands, thereby preventing a particular situation from being perceived as stressful. Although previous reports [14] indicated that patients diagnosed with lung diseases have higher rates of depression and psychological distress that general population, in this study; the psychological distress and depression rates were not higher compared to reports from general population in Jordan [26] [27].

Moreover, this study found that sociodemographic and risky life styles factors vary in their effect on the psychological and social factors. Smoking has been associated only with life satisfaction and perceived social support from friends, while working status found to associate with depression. The results, in general, do not agree with previous reports that risky life styles such smoking and clinical and demographic characteristic of patients do exacerbate patients' psychological status [1] [4] [11] [13] [17]. Although one third of the patients in this study had moderate to severe depression and that correlation found between depression and all other psychosocial factors, only life satisfaction found to be significant predictor. These finding has some agreement with previous international reports [11] that the majority of the patients in this study with pulmonary diseases had depressive feelings, and that depression increases morbidity and functional limitation. One limitation for this study is that data were cross sectional. A longitudinal study may allow better understanding for a cumulative experience over long period of time. 


\section{Conclusion}

Psychological disturbances are common in hospitalized patients with pulmonary diseases and may exacerbate patients' physical stability and negatively affect their quality of life [7]. This study found that Jordanian patients with lung disease were suffering psychological and social disturbances; however, they were able to manage and maintain their function ability that affected positively their satisfaction about their life and their ability to use effective coping skills. This study also found that older patients are more likely to have higher level of support from friends and others, higher level of life satisfaction, lower level of support from friends and moderate level of psychological distress. The study has an implication for health professionals at the community and primary care settings. There is a need to assess and screen for psychosocial factors: depression, stress, social support, life satisfaction and coping skills among patients with lung diseases in their routine checkups and visits to outpatients units. Health professionals may use screening instruments for this purpose. This will also require using comprehensive approach leading to early detection of psychological disturbances and implementation of effective treatment plan. Further studies are recommended focusing on implementing effective screening measures and intervention for psychological and social disturbances among patients diagnosed with pulmonary disease.

\section{References}

[1] Doumit, J. and Nasser, R. (2010) Quality of Life and Wellbeing of the Elderly in Lebanese Nursing Homes. International Journal of Health Care Quality Assurance, 23, 72-93. http://dx.doi.org/10.1108/09526861011010695

[2] Sareen, J., Cox, B.J., Clara, I. and Asmundson, G. (2005) The Relationship between Anxiety Disorders and Physical Disorders in the US National Comorbidity Survey. Depression and Anxiety, 21, 193-202. http://dx.doi.org/10.1002/da.20072

[3] Harter, M.C., Conway, K.P. and Merikangas, K.R. (2003) Associations between Anxiety Disorders and Physical Illness. European Archive of Psychiatry and Clinical Neuroscience, 253, 313-320. http://dx.doi.org/10.1007/s00406-003-0449-y

[4] Katon, W., Lin, E.H. and Kroenke, K. (2007) The Association of Depression and Anxiety with Medical Symptom Burden in Patients with Chronic Medical Illness. General Hospital Psychiatry, 29, 147-155. http://dx.doi.org/10.1016/j.genhosppsych.2006.11.005

[5] American Psychiatric Association (2000) Diagnostic and Statistical Manual of Mental Disorders. 4th Edition, Text Revision, American Psychiatric Association, Washington DC.

[6] Ciechanowski, P.S., Katon, W.J. and Russo, J.E. (2000) Depression and Diabetes: Impact of Depressive Symptoms on Adherence, Function, and Costs. Archive of Internal Medicine, 160, 3278-3285. http://dx.doi.org/10.1001/archinte.160.21.3278

[7] Alonso, J., Ferrer, M. and Gandek, B. (2004) Health-Related Quality of Life Associated with Chronic Conditions in Eight Countries: Results from the International Quality of Life Assessment (IQOLA) Project. Quality of Life Research, 13, 283-298. http://dx.doi.org/10.1023/B:QURE.0000018472.46236.05

[8] Oga, T., Nishimura, K., Tsukino, M., Sato, S., Hajiro, T. and Mishimaura, K. (2002) Relationship between Different Indices of Exercise Capacity and Clinical Measures in Patients with Chronic Obstructive Pulmonary Disease. Heart and Lung, 31, 374-381. http://dx.doi.org/10.1067/mhl.2002.127941

[9] Peruzza, S., Sergi, G., Vianello, A., et al. (2003) Chronic Obstructive Pulmonary Disease (COPD) in Elderly Subjects: Impact on Functional Status and Quality of Life. Respiratory Medicine, 97, 612-617. http://dx.doi.org/10.1053/rmed.2003.1488

[10] Merikangas, K.R., Ames, M., Cui, L., et al. (2007) The Impact of Comorbidity of Mental and Physical Conditions on Role Disability in the US Adult Household Population. Archive of General Psychiatry, 64, 1180-1188. http://dx.doi.org/10.1001/archpsyc.64.10.1180

[11] Stein, M.B., Cox, B.J., Afifi, T.O., Belik, S.L. and Sareen, J. (2006) Does Co-Morbid Depressive Illness Magnify the Impact of Chronic Physical Illness? A Population-Based Perspective. Psychological Medicine, 36, 587-596. http://dx.doi.org/10.1017/S0033291706007239

[12] MacDonald, B.H. (2001) Quality of Life in Cancer Care: Patients’ Experiences and Nurses' Contribution. European Journal of Oncology Nursing, 5, 32-41. http://dx.doi.org/10.1054/ejon.2000.0118

[13] Zhang, C.X., Chen, Y.M. and Chen, W.Q. (2008) Association of Psychosocial Factors with Anxiety and Depressive Symptoms in Chinese Patients with Type 2 Diabetes. Diabetes Research and Clinical Practice, 79, 523-530. http://dx.doi.org/10.1016/j.diabres.2007.10.014

[14] Wagena, E.J., Arrindell, W.A., Wouters, E.F. and van Schayack, C.P. (2005) Are Patients with COPD Psychologically 
Distressed? European Respiratory Journal, 26, 242-248. http://dx.doi.org/10.1183/09031936.05.00010604

[15] Niti, M., Ng, T., Kua, E.H., Ho, R.C.M. and Tan, C.H. (2007) Depression and Chronic Medical Illnesses in Asian Older Adults: The Role of Subjective Health and Functional Status. International Journal of Geriatric Psychiatry, 22, 1087-1094. http://dx.doi.org/10.1002/gps.1789

[16] Rozanski, A., Blumenthal, J.A., Davidson, K.W., Saab, P.G. and Kubzansky, L. (2005) The Epidemiology, Pathophysiology, and Management of Psychosocial Risk Factors in Cardiac Practice: The Emerging Field of Behavioral Cardiology. Journal of American College of Cardiology, 45, 637-651. http://dx.doi.org/10.1016/j.jacc.2004.12.005

[17] Brislin, R.W. (1970) Back Translation for the Cross-Cultural Research. Journal of Cross Cultural Research, 1, 185216. http://dx.doi.org/10.1177/135910457000100301

[18] Chapman, D.W. and Carter, J.F. (1979) Translation Procedures for Cross Cultural Use of Measurement Instrument. Education Evaluation and Policy Analysis, 1, 71-76. http://dx.doi.org/10.3102/01623737001003071

[19] Zimet, G.D., Dahlem, N.W., Zimet, S.G. and Farley, G.K. (1988) The Multidimensional Scale of Perceived Social Support. Journal of Personality Assessment, 52, 30-41. http://dx.doi.org/10.1207/s15327752jpa5201_2

[20] Beck, G., Steer, R. and Brown, G. (1996) Manual for the Beck Depression Inventory-II. Psychological Corporation, San Antonio.

[21] Lemyre, L., Tessier, R. and Eillion, L. (1990) Mesure du stress psychotogique (MSP): Manuel d’utilisation. Brossard, Quebec.

[22] Carver, C.S. (1997) You Want to Measure Coping but Your Protocol's Too Long: Consider the Brief COPE. International Journal of Behavioral Medicine, 4, 92-100. http://dx.doi.org/10.1207/s15327558ijbm0401_6

[23] Diener, E., Emmons, R.A., Larsen, R.J. and Griffin, S. (1985) The Satisfaction with Life Scale. Journal of Personality Assessment, 49, 71-75. http://dx.doi.org/10.1207/s15327752jpa4901_13

[24] Honyashiki, M., Ferri, C.P., Acosta, D., Guerra, M. and Huang, Y. (2011) Chronic Diseases among Older People and Co-Resident Psychological Morbidity: A 10/66 Dementia Research Group Population-Based Survey. International Psychogeriatric Association, 23, 1489-1501. http://dx.doi.org/10.1017/S1041610211000500

[25] Cohen, S., Underwood, L.G. and Gottlieb, B.H. (1988) Social Relationships and Health. In: Cohen, S., Underwood, L.G. and Gottlieb, B.H., Eds., Social Support Measurement and Intervention: A Guide for Health and Social Scientists, Oxford University Press, New York.

[26] Hamdan-Mansour, A., Halabi, J. and Dawani, H. (2009) Depression, Hostility, and Substance Use among University Students in Jordan. Mental Health and Substance Use: Dual Diagnosis, 2, 53-64. http://dx.doi.org/10.1080/17523280802593301

[27] Khalil, A., DarAwwad, M., Al-Gamal, E. and Hamdan-Mansour, A. (2012) Predictors of Dietary and Fluid Nonadherence in Jordanian Patients with End-Stage Renal Disease Receiving Hemodialysis: A Cross-Sectional Study. Journal of Clinical Nursing, 22, 127-136. http://dx.doi.org/10.1111/j.1365-2702.2012.04117.x 